DOI: 10.12731/2070-7568-2020-3-124-141

УДК 336.714

\title{
ВЛИЯНИЕ КОРОНАВИРУСА НА ЭКОНОМИКУ РОССИИ
}

Кузьменкова В.Д.

Эпидемия коронавируса (COVID-19) является коварным заболеванием, которое быстро распространяется по всему миру, оказывая отрицательное воздействие на все человеческое сообщество. COVID-19 влияет на здоровье людей, на все сферы деятельности, как внутри страны, так и за ее предель.

В статье рассмотрены влияние пандемии на экономику России и направления его снижения. Анализируются экономические последствия на основе экспертных оченок, опубликованных в средствах массовой информации.

Цель: изучение современного состояния экономики России в условиях эпидемии коронавируса для предложения путей выхода из мирового кризиса.

Метод или методология проведения работы: общенаучные, экономико-математические, статистические, метод экспертных оценок и т.д.

Результаты: в статье сформулированы основные направления выхода России из кризиса.

Область применения результатов: полученные результаты целесообразно применять при разработке стратегии и тактики выхода России из кризиса.

Ключевые слова: коронавирус; российская экономика; государственные меры поддержки; мировая экономика; жизнеобеспечиваюшие сферы; ограничения.

\section{IMPACT OF CORONAVIRUS ON THE RUSSIAN ECONOMY}

\section{Kuzmenkova V.D.}

The coronavirus epidemic (COVID-19) is an insidious disease that is spreading rapidly around the world, negatively affecting the entire human community. COVID-19 affects people's health, all areas of activity, both inside and outside the country. 
The article examines the impact of the pandemic on the Russian economy and the ways to reduce it. The economic consequences are analyzed on the basis of expert assessments published in the mass media.

Objective: to study the current state of the Russian economy in the context of the coronavirus epidemic in order to suggest ways out of the global crisis.

Method or methodology of the work: General scientific, economic and mathematical, statistical, expert assessment method, etc.

Results: the article outlines the main directions of Russia's recovery from the crisis.

Scope of the results: the results obtained should be used in the development of strategies and tactics for Russia's recovery from the crisis.

Keywords: coronavirus; Russian economy; state support measures; world economy; life-supporting areas; restrictions.

\section{Введение}

Пандемия COVID-19 разрушительно воздействуя на экономику, поставила в тупик международное сообщество.

Эпидемия началась в Китае и распространяется в другие страны. Россия также попала в ее зону со всеми вытекающими последствиями.

Пандемия COVID-19 наложила отпечаток не только на бизнес, но и на жизнь россиян, т.к. большинство организаций приостанавливали свою деятельность, некоторые закрыты до сих пор.

Отличительной чертой пандемии COVID-19 является то, что наибольший уровень заболеваемости выявлен в странах с высоким уровнем социально-экономического развития: в Италии, Испании, США, Германии, Китае, Франции, Великобритании, Швейцарии, Бельгии, Нидерландах, Канаде [20]. Это может быть связано в том числе, с высоким уровнем мобильности граждан, вышеназванных государств.

Целью работы является изучение современного состояния экономики России в условиях эпидемии коронавируса, выделение тенденций и их анализ, имеющих решающее значение при разработке путей решения выхода из мирового кризиса. 
Основными задачами работы являются изучение, анализ, обобщение мирового опыта, формирование и разработка основных направлений тактики выхода из кризиса.

\section{Методология исследования}

Основным методом получения информации для работы стало изучение материалов электронных библиотек, архивов экономических журналов и т.д. Такие методы как синтез, аналогия и обобщение были использованы для систематизации информации, а также для получения выводов из проведенного исследования.

\section{Результаты и обсуждение}

C начала эпидемии COVID-19, многие мировые отрасли экономики столкнулись с проблемами, которые появились из-за сдерживающих мер по распространению эпидемии из Китая: приостановка производств и торговой деятельности и т.д. Затем, другие страны (Южная Корея, Италия и т.д.) начали применять подобные меры, последовало резкое снижение спроса и предложения [26]. Восстановление экономики Китая ожидалось по мере возвращения трудящихся на свои рабочие места в конце апреля текущего года [27]. Аналитические оценки экспертов прогнозируют упадок мировой экономики в 2020 году в пределах 3-5\% от уровня 2019 года [8].

Международные организации все чаще признают, что биологические угрозы оказывают серьезное влияние не только на здравоохранение, но и наносят глобальный ущерб другим секторам экономики [23].

Как показало исследование, проведенное компанией Euler Hermes из-за пандемии COVID-19, пострадает большая часть отраслей экономики. Так в I квартале 2020 года зафиксирована максимальная точка падение рейтинга рисков в 126 отраслях, что является самым наибольшим с 2012 года. Падение спроса произошло из-за воздействия COVID-19 (5 из 10 понижений), рентабельность (4 из 10) и ликвидность (1 из 10). В 6 из 10 случаев понижение составляет от «среднего» до «чувствительного» уровня риска [29]. 
Анализ ослабления экономической активности в России является неточным. Данные прогноза снижения ВВП России отличаются от -4,3\% (консенсус-прогноз НИУ ВШЭ) до -6\% (прогноз Всемирного банка) и -6,6\% (прогноз МВФ). Среднее значение снижение \% ВВП составляет $-5,4 \%$, что выше прогнозных показателей мая 2020 г. (среднее значение $-4,1 \%$ ) (рисунок 4).

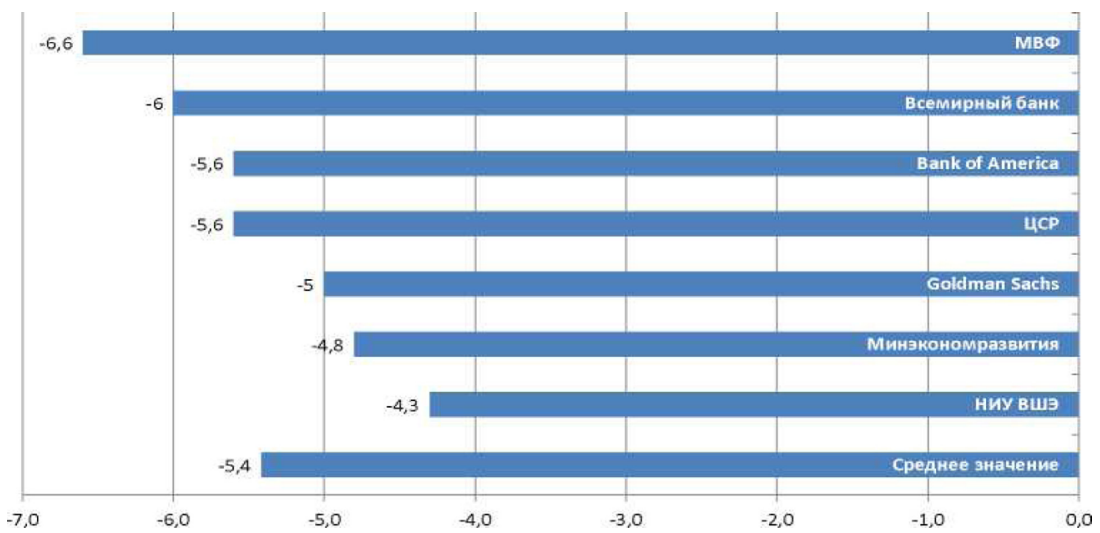

Рис. 4. Оценки снижения ВВП России в 2020 г., \% [1]

На 2020 и последующие годы в России планировался экономический рост на уровне 2 и более \%. Пандемия коронавируса в России начала влиять на жизнь в стране с конца марта текущего года, хотя и в меньшей степени, чем в других странах. Темпы роста реальных располагаемых доходов населения должны были повыситься на 2,2$2,4 \%$ [6]. Но из-за снижения спроса на природные ресурсы России на мировых рынках, из-за приостановки производств в странах-импортеpax нашего сырья, наше государство ощущает негативные процессы.

Большое влияние на углубление кризиса оказало падение цен на нефть, что повлекло за собой снижение доходов госбюджета. В случае нового соглашения ОПЕК+, даже если цены на нефть вырастут, вероятно значительно снизятся объемы этих поставок.

Воздействие коронавируса на экономику России распространяется на все сферы деятельности, отражается на разных направлениях, формах, степенью последствий. 
Бизнес-омбудсмена Б. Титов в своем докладе Президенту РФ отметил, что «пандемия COVID-19 в России затронула порядка 4,17 млн компаний и ИП от общего числа 6,05 млн, то есть до 67\% малых, средних и крупных предприятий и ИП» [9].

Также прогноз Центра стратегических разработок, основанный на экономических ожиданиях бизнеса показал, что в 2020 году доля государства в общей выручке по экономике может вырасти на 0,5 п.п. и составить 27,5\%, а доля субъектов малого и среднего предпринимательства (МСП), может сократиться на 1 п.П. и составить $16,1 \%$. [10].

По оценкам самих предпринимателей, только для 21\% предприятий могут привести к банкротству последствия пандемии [11].

Целые направления отраслей были вынужденно частично прекратить свою деятельность, прежде всего, это сферы розничной и мелкооптовой торговли, сфера услуг, работа детских садов, учебных заведений, библиотек, центров дополнительного образования и досуга и т.д. Даже когда эпидемия закончится, снизится потребительский спрос и производство.

Большие убытки несут микропредприятия, ИП, самозанятые, которые оказывают услуги по ремонту техники, развлекательные и организационные услуги и т.д.

Проявляются с большей силой проблемы автомобилестроительной отрасли, у которой снижение рынка в 2020 году уже составило более 10\% (в 2019 году снижение рынка было около 4\%).

Оптовая и розничная торговля теряет от прекращения отношений широкомасштабных связей поставок и т.д. Мировое сообщество в настоящее время не сможет восстановить свою производственную активность и, как следствие, спрос на энергоресурсы России [19].

По данным ФНС России, определен список отраслей, наиболее пострадавших из-за распространения коронавирусной инфекции (таблица 1), который утвержден Постановлением Правительства от 03.04.2020г. № 434 [5]. 
Таблицуа 1.

Отрасли, наиболее пострадавшие от коронавирусной инфекции

\begin{tabular}{|c|c|c|}
\hline \multirow{15}{*}{$\begin{array}{l}\text { Наиболее } \\
\text { пострадавшие } \\
\text { отрасли }\end{array}$} & Отрасли & \multirow{15}{*}{$\begin{array}{l}\text { Затронуты 6,7 млн. } \\
\text { человек. Из них } \\
3,4 \text { млн. в сфере } \\
\text { малого и среднего } \\
\text { предпринимательства }\end{array}$} \\
\hline & Воздушный транспорт & \\
\hline & Водный транспорт & \\
\hline & Железнодорожный транспорт & \\
\hline & Туризм & \\
\hline & Выставочная деятельность & \\
\hline & Гостиницы & \\
\hline & Сфера развлечений и досуга & \\
\hline & Общественное питание & \\
\hline & Бытовые услуги & \\
\hline & Культура и спорт & \\
\hline & Непродовольственный ритейл & \\
\hline & Стоматологические услуги & \\
\hline & Дополнительное образование & \\
\hline & СМИ & \\
\hline
\end{tabular}

В мире складываются тенденции на ограничения и запрет экспорта определенных групп товаров, что обусловливает рост цен и пересмотр логистических цепочек.

Под влиянием ограничительных мер по сдерживанию эпидемии коронавируса, деловая активность российской экономики остается низкой.

Согласно данным опросов НАФИ [12] только 43\% бизнесменов считают возможным восстановление в срок не менее года, порядка 14\% оценивают период восстановления в рамках двух-трех лет. По оценке ЦСР [13], к лету 2021 года доля восстановившихся компаний составит лишь порядка 66\%. При этом 15\% компаний не уверены, достигнет ли выручка докризисного уровня к 2023 году.

Таблицуа 2.

Динамика основных экономических показателей России за 2019-2020 годы

\begin{tabular}{|l|c|c|c|c|c|c|}
\hline & 2019 г. & $\begin{array}{c}\text { IV кв. } \\
2019 \text { г. }\end{array}$ & $\begin{array}{c}\text { I кв. } \\
2020 \text { г. }\end{array}$ & $\begin{array}{c}\text { Март } \\
2020 \text { г. }\end{array}$ & $\begin{array}{c}\text { Апрель } \\
2020 \text { г. }\end{array}$ & $\begin{array}{c}\text { Май } \\
2020 \text { г. }\end{array}$ \\
\hline \multicolumn{7}{|l|}{ Агрегированный выпуск и опережающие индикаторы } \\
\hline ВВП & 1,3 & 2,1 & 1,6 & - & - & - \\
\hline $\begin{array}{l}\text { Выпуск товаров и } \\
\text { услуг по базовым } \\
\begin{array}{l}\text { видам экономической } \\
\text { деятельности }\end{array}\end{array}$ & 2,0 & 2,7 & 2,3 & 1,0 & $-9,9$ & -10 \\
\hline
\end{tabular}


Окончание табл. 2.

\begin{tabular}{|c|c|c|c|c|c|c|}
\hline $\begin{array}{l}\text { Потребление } \\
\text { электроэнергии }\end{array}$ & 1,2 & 1,1 & $-0,6$ & $-1,1$ & $-2,9$ & $-5,4$ \\
\hline \multicolumn{7}{|c|}{ Производственная и инвестиционная активность } \\
\hline $\begin{array}{l}\text { Промышленное } \\
\text { производство }\end{array}$ & 2,3 & 1,8 & 1,5 & 0,3 & $-6,6$ & $-9,6$ \\
\hline $\begin{array}{l}\text { Производство } \\
\text { сельхозпродукции }\end{array}$ & 4,0 & 5,3 & 3,0 & 3,0 & 3,1 & 3,2 \\
\hline Объем строительства & 0,6 & 0,9 & 1,1 & 0,1 & $-2,3$ & $-3,1$ \\
\hline Грузооборот транспорта & 0,6 & $-0,8$ & $-3,8$ & $-6,7$ & $-5,8$ & $-9,5$ \\
\hline Оборот оптовой торговли & 1,6 & 8,4 & 10,0 & 9,8 & $-11,3$ & $-12,5$ \\
\hline АМОС (вклад в АВВП, п.п.) & 0,5 & 2,0 & $0,5-1,5$ & - & - & - \\
\hline \multicolumn{7}{|c|}{ Инвестиционная активность } \\
\hline $\begin{array}{l}\text { Инвестиции в основной } \\
\text { капитал }\end{array}$ & 1,7 & 2,3 & 1,2 & - & - & - \\
\hline $\mathrm{BHOK}$ & 1,5 & 2,9 & $1,0-2,0$ & - & - & - \\
\hline \multicolumn{7}{|l|}{ Рынок труда } \\
\hline $\begin{array}{l}\text { Уровень безработицы / } \\
\text { исключениесезонности } \\
\text { (\% от рабочей силы) }\end{array}$ & 4,6 & $4,6 / 4,5$ & $4,6 / 4,4$ & $4,7 / 4,6$ & $5,8 / 5,7$ & $6,1 / 6,1$ \\
\hline $\begin{array}{l}\text { Номинальная заработная } \\
\text { плата }\end{array}$ & 9,5 & 8,2 & 8,8 & 8,6 & 1,0 & \\
\hline $\begin{array}{l}\text { Реальная заработная } \\
\text { плата }\end{array}$ & 4,8 & 4,6 & 6,2 & 5,9 & $-2,0$ & \\
\hline \multicolumn{7}{|c|}{ Доходы, сбережения и потребительская активность } \\
\hline $\begin{array}{l}\text { Реальные располагаемые } \\
\text { денежные доходы } \\
\text { населения }\end{array}$ & 1,0 & 1,8 & $-0,2$ & - & - & - \\
\hline $\begin{array}{l}\text { Расходы на конечное } \\
\text { потребление домашних } \\
\text { хозяйств }\end{array}$ & 2,5 & 2,5 & $2,5-3,5$ & - & - & - \\
\hline Норма сбережений & 10,0 & 12,0 & 6,3 & - & - & - \\
\hline $\begin{array}{l}\text { Оборот розничной } \\
\text { торговли }\end{array}$ & 1,9 & 2,1 & 4,4 & 5,7 & $-23,2$ & $-19,2$ \\
\hline $\begin{array}{l}\text { Объем платных услуг } \\
\text { населению }\end{array}$ & $-0,9$ & $-1,4$ & $-0,8$ & $-5,4$ & $-37,9$ & $-39,5$ \\
\hline
\end{tabular}

(прирост в \% к соответствующему периоду предыдущего года)

Источники: Росстат, расчеты Банка России [7].

Анализ данных таблицы 2 показывает, что мировая экономика, со времен 1-й и 2-й Мировых войн не была так близка к полному крушению, а российская экономика следует в направлении крупнейшего кризиса. Например, во время мирового финансового кризиса 
2009 года, ВВП России снизился на 8\%, а в критическом 1998 году падение оценивалось на 5,3\% [3].

Такие же проблемы решают, что и наша экономика, развитые и развивающиеся страны. Но значительное большинство стран избрали другую стратегию выхода из кризиса, включающую стимулирование спроса, поддержку предприятий путем прямых грантов, специальных кредитных продуктов и сниженных ставок по налогам и продолжение поддержки спроса на этапе снятия ограничительных мероприятий (например, в Чехии, Австрии, Норвегии).

Данные меры на первом этапе позволили этим странам создать запас прочности для экономики и реализации последующих более точечных мер на этапе выхода из кризиса.

Используемый зарубежными странами набор применяемых, финансовых инструментов, можно разделить на следующие группы:

- Поддержание внутреннего потребительского и государственного спроса:

- Поддержание корпоративного сектора, включающие налоговые меры и повышение доступа предприятий к финансовым ресурсам:

- Активизация ресурсов финансовой и бюджетной систем для поддержания экономического роста.

Так, на пример, в Китайской народной республике, для поддержки предприятий, оказывающих медицинские услуги, услуги общественного питания и размещения, а также различные персональные услуги, полностью освободили их от уплаты НДС. Кроме того, отказались от взносов в систему социального обеспечения [31].

Правительство США, с целью поддержки корпоративного сектора, предоставили финансовую помощь крупным и малым предприятиям, потерявшим всех или большую часть своих клиентов в последние недели; профинансировали компании, вынужденные прекратить работу, с целью предотвращения увольнений сотрудников и т.д.

Для обеспечения устойчивости внутреннего потребительского спроса, приостановили выплаты по ипотечным кредитам на срок 
до 12 месяцев для лиц, зараженных Covid-19; увеличили временно пособия безработным т.д. [32].

На предприятиях Чешской республики, на которых деятельность была приостановлена из-за пандемии, производится софинансирование ФОТ (80\% от ФОТ); самозанятые могут получить единовременную выплату до 25000 чешских крон; представляются Государственные кредитные гарантии (33,3 млрд. евро); ЦБ Чехии снизил ключевую ставку на 50б.п. и 75 б.п до 1\% и т.д. [33].

Проведенный анализ развития бизнеса в России показал, что частичная или полная потеря доходов населением, вызванная внешними и внутренними экономическими факторами, требует безотлагательных, стимулирующих мер поддержки со стороны государства [4].

Президент В.В. Путин, в своем обращении к гражданам 25 марта 2020 года, представил ряд мер, направленных на поддержку экономики России в условиях распространения коронавирусной [15]:

1. Обеспечение товарами первой необходимости и поддержка населения (для чего необходимо проводить непрерывный мониторинг потребительских цен; достаточного наличия в продаже товаров первой необходимости; проводить реализацию мер активной поддержки занятости).

2. Поддержка отраслей экономики, оказавшихся в зоне риска (освобождение туроператоров от уплаты взносов и установление компенсации их убытков; предоставление отсрочки по налоговым платежам сроком на 3 месяца организациям и отраслям, наиболее пострадавшим от пандемии.

3. Поддержка малого и среднего предпринимательства (отсрочка уплаты арендных платежей в случае с использованием государственного или муниципального имущества; предоставление форм льготного кредитования).

4. Общесистемные меры (создание финансового резерва в размере до 300 миллиардов рублей; создание гарантийного фонда для реструктуризации) и т.д.

Так на сегодняшний день в России на поддержку граждан и предпринимателей государство готово выделить порядка 2-2,5\% от ВВП, 
для сравнения правительство США выделило на данные цели 20\% ВВП, страны Евросоюза в среднем по 8-10\%, Япония - 10\%. Если анализировать меры господдержки в стоимостном эквиваленте, то Правительство РФ выделило около 300 млрд. руб. на реализацию пакета антикризисных мер и борьбу с коронавирусной инфекцией в стране. Таким образом, исходя из текущего курса рубля к доллару и евро, государственная поддержка национальной экономики нашей страны в 10 раз меньше, чем аналогичные меры в Великобритании, в 58 раз Испании и в 263 раза американских вливаний в собственную экономику [16].

Правительство России предполагает, что мероприятиями, направленные на поддержку населения, смогут воспользоваться более 5 млн чел., а набором финансовых инструментов, предложенные на поддержку предприятий и занятости - 526 тыс. индивидуальных предпринимателей и предприятий, на которых трудоустроено 5,3 млн. чел. [34]. К наиболее востребованными введенным мерам поддержки, по мнению предпринимателей, относящихся к пострадавшим отраслям в соответствии с постановлениями Правительства РФ, были отнесены: отсрочка по всем налоговым платежам, снижение размера страховых взносов до 15\%, а также снижение ставок по упрощённой системе налогообложения.

По итогам проведенного исследования коммерческих тенденций в России, меры господдержки экономики стали эффективным инструментом ее восстановления, но, как показывает анализ, недостаточными.

Используя международный опыт, для устранения негативных последствий пандемии для экономики, необходимо в России предусмотреть реализацию дополнительных мер поддержки:

1.Для сохранения занятости населения:

- произвести полное освобождение от налогов для предприятий МСП, на специальных режимах налогообложения сроком не менее одного года;

- оказать финансовую поддержку крупным и малым предприятиям, которые потеряли всех или большую часть своих клиентов в последние месяцы; 
- использовать мораторий на принудительное взыскание задолженностей и процедуры банкротства;

- представить отсрочку платежей по кредитам для МСП и домохозяйств;

- «заморозить» действующие энерготарифы на 2020-2021 годы.

2. Для поддержания спроса:

- софинансировать ФОТ на предприятиях, чья деятельность была приостановлена из-за пандемии ( $80 \%$ от ФОТ);

- освободить предприятия от уплаты страховых взносов на обязательное пенсионное страхование до 01.01.2021г;

- увеличить пособие по безработице;

- субсидировать коммунальные платежи.

От решений, принимаемых государством, зависит эффективность выхода России из кризиса, поэтому важно использовать вспышку COVID-19 для совершенствования стратегий антикризисного управления и укрепления международных и внутренних механизмов координации и взаимодействия по минимизации последствий кризиса.

\section{Выводы}

На нашей планете существует 1,67 млн неизвестных вирусов, из них от 631 тыс. до 827 тыс. могут быть потенциально опасны для человека [21].

Современная экономика, определенно, не сталкивалась еще с такой мировой проблемой. Эта болезнь откладывает отпечаток не только на экономику, но и на социальную жизнь общества.

Увеличение мобильности населения, развитие торговли и туризма - выделяются как факторы, способствующие распространению эпидемий [22]. Государство должно вынести «уроки кризиса».

Опыт России показывает, что фирмы, принимающие во внимание благополучие своих сотрудников, поставщиков и клиентов в той же степени, что и интересы своих акционеров, имеют возможность пережить кризис лучше других. Каждой фирме предстоит сыграть свою роль в переходе к новой экономической системе. 


\section{Список литературы}

1. Дробот Е.В, Макаров И.Н., Назаренко В.С. Влияние пандемии COVID-19 на реальный сектор экономики // Экономика, предпринимательство и право, т. 10, № 8, 2020.

2. Максимова Е.В., Морозов В.В. Экономический рост и интеграция в новой модели мировой экономики: выводы для России. // Научно-аналитический журнал «Инновации и инвестиции». 2019. №11. С. 64-68.

3. Финансово-экономические кризисы последних десятилетий и их влияние на экономику России // Прайм [электронный ресурс] https://1 prime.ru/sience/20190402/8298 58467.html.

4. Материалы Банка России. Экономика: факты, оценки, комментарии [электронный ресурc]. https://cbr.ru/Collection/Collection/File/29098/ EC_2020-06.pdf.

5. Постановление Правительства РФ от 3 апреля 2020 г. N 434 «Об утверждении перечня отраслей российской экономики, в наибольшей степени пострадавших в условиях ухудшения ситуации в результате распространения новой коронавирусной инфекции» // Система ГАРАНТ. http://base.garant.ru/73846630/\#ixzz6gp3DFHsf

6. Прогноз социально-экономического развития Российской Федерации на период до 2024 года. https://www.economy.gov.ru/material/directions/ makroec/prognozy_socialno_ekonomicheskogo_razvitiya/prognoz socialno_ekonomicheskogo_razvitiya_rf_na_period_do_2024_goda_.html

7. Экономика: факты, оценки, комментарии (май 2020 г.) [электронный реcypc] // „https://www.cbr.ru/collection/collection/file/27991/ec_2020-05.pdf

8. Аналитики оценили ущерб экономике России от коронавируса [электронный ресурс] // РБК. https://www.rbc.ru/economics/04/02/2020/5e 3986b99a79473a58036d5a/

9. COVID-19. Последствия для бизнеса и экономики [электронный pecypc]. URL: http://doklad. ombudsmanbiz.ru/2020/7.pdf .

10. По данным единой межведомственной информационной статистической системы [электронный ресурс]. URL: https://www.fedstat.ru/.

11. Карта самочувствия бизнеса [электронный ресурc]. URL: https:// smarteka.com/solution/map

12. Российский бизнес и коронавирус. Ч. 1. Предприниматели о влиянии эпидемии на их бизнес и о потребности в господдержке [электронный ресурс]. 
URL: https://nafi.ru/projects/predprinimatelstvo/ rossiyskiy-biznes-i-koronavirus-chast-1-predprinimateli-o-vliyanii-epidemii-na-ikh-biznesi- o-potreb

13. Материалы ЦСР. Аналитический бюллетень «Пульс экономики» [электронный ресурc]. URL: https://www.csr.ru/ru/

14. Экономика: факты, оценки, комментарии (июнь 2020 г.) // Экономика, № 6(54). июнь, 2020 [электронный pecypc]. https://cbr.ru/ Collection/Collection/File/29098/EC_2020-06.pdf.

15. План первоочередных мероприятий по обеспечению устойчивого развития экономики в условиях ухудшения ситуации в связи с распространением новой коронавирусной инфекции [электронный ресурс] // Минэкономразвитие РФ. https://www.economy.gov.ru/material/news/ ekonomika_bez_virusa/plan_pervoocherednyh_meropriyatiy_po_obespecheniyu_ustoychivogo_razvitiya_ekonomiki_v_usloviyah_uhudsheniya_situacii_v_svyazi_s_rasprostraneniem_novoy_koronavirusnoy_infekcii.html

16. Страшен не вирус, а кризис. Как пандемия и обвал рубля отразятся на российской экономике // Правмир [электронный ресурс]. https:// www.pravmir.ru/strashen-ne-virus-a-krizis-kak-pandemiya-i-obvalrublya-otrazyatsya-na-rossijskoj-ekonomike/

17. COVID-19 Dashboard by the Center for Systems Science and Engineering (CSSE) at Johns Hopkins University (JHU). https://www.arcgis.com/ apps/opsdashboard/index.html\#/bda7594740fd40299423467b48e9ecf6

18. Covid-19: After a lost quarter, $75 \%$ of the Chinese economy is back [electronic resource]. URL: https://www.eulerhermes.com/en_global/ economic-research/news/covid-19-after-a-lost-quarter-75-percent-ofthe-chinese-economy-is-back.html

19.https://www.rbc.ru/economics/18/03/2020/5e707a7a9a7947ec6fa0a06d 20. Coronavirus COVID-19 Global Cases by the Center for Systems Science and Engineering (CSSE) at Johns Hopkins University (JHU) [electronic resource]. URL: https://coronavirus.jhu.edu/map.html

21. Robert Kessler Disease X: The Next Pandemic [electronic resource]. URL: https://www.ecohealthalliance.org/2018/03/disease-X

22 . World at Risk. Annual report on global preparedness for health emergencies. Global Preparedness Monitoring Board. Geneva: World Health Organization. 2019 [electronic resource]. URL: https://apps.who.int/ gpmb/assets/annual_report/GPMB_annualreport_2019.pdf 
23. United Nations Development Group - Western and Central Africa, SocioEconomic Impact of Ebola Virus Disease in West African Countries, 2015. [electronic resource]. URL: https://www.undp.org/content/dam/ $\mathrm{rba} /$ docs/Reports/ebola-west-africa.pdf

24. Choularton R., Mallory M. Opinion: How to address the impact of COVID-19 on global food systems [electronic resource]. URL: https:// www.devex.com/news/sponsored/opinion-how-to-address-the-impactof-covid-19-on-global-food-systems-96892

25. Coronavirus COVID-19 Global Cases by the Center for Systems Science and Engineering (CSSE) at Johns Hopkins University (JHU). https://www.arcgis.com/apps/opsdashboard/index.html\#/bda7594740fd40299423467b48e9ecf6

26. Covid-19: After a lost quarter, $75 \%$ of the Chinese economy is back [electronic resource]. URL: https://www.eulerhermes.com/en_global/ economic-research/news/covid-19-after-a-lost-quarter-75-percent-ofthe-chinese-economy-is-back.html

27. United Nations Development Group - Western and Central Africa, SocioEconomic Impact of Ebola Virus Disease in West African Countries, 2015. [electronic resource]. URL: https://www.undp.org/content/dam/ $\mathrm{rba/docs/Reports/ebola-west-africa.pdf}$

28. Lemerle M., Livinec M., Hillenbrand-Saponar C., Duthoit A. No stone unturned: How Covid-19 is disrupting every industry [electronic resource]. URL: https://www.eulerhermes.com/en_global/economic-research/insights/no-stone-unturned-how- covid19-is-disrupting-every-industry.html

29. Choularton R., Mallory M. Opinion: How to address the impact of COVID-19 on global food systems [electronic resource]. URL: https:// www.devex.com/news/sponsored/ opinion-how-to-address-the-impactof-covid-19-on-global-food-systems-96892

30.https://www.internationaltaxreview.com/article/b1 kjjn20mxcfyj/china-announces-tax-relief-

31.https://www.rbc.ru/economics/25/03/2020/5e7b121a9a7947c38e4c3823; https://www.congress.gov/116/bills/hr6074/BILLS-116hr6074enr.pdf; https://www.congress.gov/bill/116th-congress/house-bill/6201

32.https://www.imf.Org/en/Topics/imf-and-covid19/Policy-Responses-to-COVID-19\#A. 
33. http://government.ru/static/main/GOV-COVID-HELP.html

34. Robert Kessler Disease X: The Next Pandemic [electronic resource]. URL: https://www.ecohealthalliance.org/2018/03/disease-x

35. World at Risk. Annual report on global preparedness for health emergencies. Global Preparedness Monitoring Board. Geneva: World Health Organization. 2019. [electronic resource]. URL: https://apps.who.int/ gpmb/assets/annual_report/ PMB_annualreport_2019.pdf

\section{References}

1. Drobot E.V., Makarov I.N., Nazarenko V.S. The impact of the COVID-19 pandemic on the real sector of the economy // Economics, Entrepreneurship and Law, vol. 10, no. 8, 2020.

2. Maksimova E.V., Morozov V.V. Economic Growth and Integration in a New Model of the World Economy: Conclusions for Russia. // Scientific-analytical journal "Innovations and investments". 2019. No. 11. S. 64-68.

3. Financial and economic crises of recent decades and their impact on the Russian economy // Prime [electronic resource] https://1prime.ru/ sience/20190402/8298 58467.html.

4. Materials of the Bank of Russia. Economics: facts, estimates, comments [electronic resource]. https://cbr.ru/Collection/Collection/File/29098/ EC_2020-06.pdf.

5. Decree of the Government of the Russian Federation of April 3, 2020 N 434 "On approval of the list of sectors of the Russian economy most affected by the worsening situation as a result of the spread of a new coronavirus infection" // GARANT System. http://base.garant.ru/73846630/\#ixzz6gp3DFHsf

6. Forecast of social and economic development of the Russian Federation for the period up to 2024. https://www.economy.gov.ru/material/directions/ makroec/prognozy_socialno_ekonomicheskogo_razvitiya/prognoz_socialno_ekonomicheskogo_razvitiya_rf_na_period_do_2024_goda_.html

7. Economics: facts, estimates, comments (May 2020) [electronic resource] // Economics, no. 5 (53). May 2020. https://www.cbr.ru/collection/collection/file/27991/ec_2020-05.pdf

8. Analysts assessed the damage to the Russian economy from the coronavirus [electronic resource] // RBK. https://www.rbc.ru/economics/04/02/2020/5e3986b99a79473a58036d5a/ 
9. COVID-19. Consequences for business and economy [electronic resource]. URL: http: // doklad. ombudsmanbiz.ru/2020/7.pdf.

10. According to the data of the unified interdepartmental information statistical system [electronic resource]. URL: https://www.fedstat.ru/.

11. Map of business health [electronic resource]. URL: https://smarteka. com/solution/map

12. Russian business and coronavirus. Part 1. Entrepreneurs about the impact of the epidemic on their business and the need for state support [electronic resource]. URL: https://nafi.ru/projects/predprinimatelstvo/ rossiyskiy-biznes-i-koronavirus-chast-1-predprinimateli-o-vliyanii-epidemii-na-ikh-biznesi- o-potreb.

13. Materials of the CSR. Analytical bulletin "Pulse of the economy" [electronic resource]. URL: https://www.csr.ru/ru/

14. Economy: facts, estimates, comments (June 2020) // Economy, no. 6 (54). June, 2020 [electronic resource]. https://cbr.ru/Collection/Collection/File/29098/EC_2020-06.pdf

15. A plan of priority measures to ensure sustainable economic development in the context of a worsening situation due to the spread of a new coronavirus infection [electronic resource] // Ministry of Economic Development of the Russian Federation. https://www.economy.gov.ru/material/news/ekonomika_bez_virusa/plan_pervoocherednyh_meropriyatiy_po_obespecheniyu_ustoychivogo_razvitiya_ekonomiki_v_usloviyah_uhudsheniya_situacinovstrans_srazvitiya_v_usloviyah_uhudsheniya_situanovstrans_s

16. It is not the virus that is terrible, but the crisis. How the pandemic and the collapse of the ruble will affect the Russian economy // Pravmir [electronic resource]. https://www.pravmir.ru/strashen-ne-virus-a-kriziskak-pandemiya-i-obval-rublya-otrazyatsya-na-rossijskoj-ekonomike/

17. COVID-19 Dashboard by the Center for Systems Science and Engineering (CSSE) at Johns Hopkins University (JHU). https:/www.arcgis.com/ apps/opsdashboard/index.html\#/bda7594740fd40299423467b48e9ecf6

18. Covid-19: After a lost quarter, $75 \%$ of the Chinese economy is back [electronic resource]. URL: https://www.eulerhermes.com/en_global/ economic-research/news/covid-19-after-a-lost-quarter-75-percent-ofthe-chinese-economy-is-back.html 
19.https: //www.rbc.ru/economics/18/03/2020/5e707a7a9a7947ec6fa0a06d 20. Coronavirus COVID-19 Global Cases by the Center for Systems Science and Engineering (CSSE) at Johns Hopkins University (JHU) [electronic resource]. URL: https://coronavirus.jhu.edu/map.html

21. Robert KesslerDisease X: The Next Pandemic [electronic resource]. URL: https:/www.ecohealthalliance.org/2018/03/disease-X

22. World at Risk. Annual report on global preparedness for health emergencies. Global Preparedness Monitoring Board. Geneva: World Health Organization. 2019 [electronic resource]. URL: https://apps.who.int/ gpmb/assets/annual_report/GPMB_annualreport_2019.pdf

23. United Nations Development Group - Western and Central Africa, Socio-Economic Impact of Ebola Virus Disease in West African Countries, 2015. [electronic resource]. URL: https://www.undp.org/content/dam/ rba/docs/Reports/ebola-west-africa.pdf

24. Choularton R., Mallory M. Opinion: How to address the impact of COVID-19 on global food systems [electronic resource]. URL: https:// www.devex.com/news/sponsored/opinion-how-to-address-the-impactof-covid-19-on-global-food-systems-96892

25. Coronavirus COVID-19 Global Cases by the Center for Systems Science and Engineering (CSSE) at Johns Hopkins University (JHU). https://www.arcgis.com/apps/opsdashboard/index.html\#/bda7594740fd40299423467b48e9ecf6

26. Covid-19: After a lost quarter, $75 \%$ of the Chinese economy is back [electronic resource]. URL: https://www.eulerhermes.com/en_global/ economic-research/news/covid-19-after-a-lost-quarter-75-percent-ofthe-chinese-economy-is-back.html

27. United Nations Development Group - Western and Central Africa, SocioEconomic Impact of Ebola Virus Disease in West African Countries, 2015. [electronic resource]. URL: https://www.undp.org/content/dam/ $\mathrm{rba} /$ docs/Reports/ebola-west-africa.pdf

28. Lemerle M., Livinec M., Hillenbrand-Saponar C., Duthoit A. No stone unturned: How Covid-19 is disrupting every industry [electronic resource]. URL: https:/www.eulerhermes.com/en_global/economic-research/insights/no-stone-unturned-how- covid19-is-disrupting-every-industry.html 
29. Choularton R., Mallory M. Opinion: How to address the impact of COVID-19 on global food systems [electronic resource]. URL: https:// www.devex.com/news/sponsored/ opinion-how-to-address-the-impactof-covid-19-on-global-food-systems-96892

30. https://www.internationaltaxreview.com/article/b1 kjjn20mxcfyj/china-announces-tax-relief-

31. https://www.rbc.ru/economics/25/03/2020/5e7b121a9a7947c38e4c3823; https://www.congress.gov/116/bills/hr6074/BILLS-116hr6074enr.pdf; https://www.congress.gov/bill/116th-congress/house-bill/6201

32.https://www.imf.Org/en/Topics/imf-and-covid19/Policy-Responses-to-COVID-19\#A.

33.http://government.ru/static/main/GOV-COVID-HELP.html

34. Robert Kessler Disease X: The Next Pandemic [electronic resource]. URL: https://www.ecohealthalliance.org/2018/03/disease-X

35. World at Risk. Annual report on global preparedness for health emergencies. Global Preparedness Monitoring Board. Geneva: World Health Organization. 2019. [electronic resource]. URL: https://apps.who.int/ gpmb/assets/annual_report/ PMB_annualreport_2019.pdf

\section{ДАННЫЕ ОБ АВТОРЕ}

Кузьменкова Вера Джабраиловна, доктор экономических наук, доцент, профессор кафедры экономики и финансов Гәсельский государственный университет пос. Электроизолятор, 67, Раменский р-н, Московская обл., 140155, Российская Федеращия 9621914395@mail.ru

\section{DATA ABOUT THE AUTHOR}

Kuzmenkova Vera Dzhabrailovna, Doctor of Economics, Associate Professor, Professor of the Department of Economics and Finance Gzhel State University Electroizolyator, 67, Ramenskiy district, Moscow region, 140155, Russian Federation 9621914395@mail.ru 